\title{
FONTES DE AMIDO E PROTEÍNA PARA VACAS LEITEIRAS EM DIETAS À BASE DE CAPIM ELEFANTE
}

\author{
Laísse Garcia de Lima ${ }^{1,3}$; Luiz Gustavo Nussio²*; José Renato Silva Gonçalves"; José Manuel \\ Correia de Simas²; Alexandre Vaz Pires²; Flávio Augusto Portela Santos² \\ ${ }^{1}$ Pós-Graduandos em Ciência Animal e Pastagens - USP/ESALQ. \\ ${ }^{2}$ Depto. de Produção Animal - USP /ESALQ, C.P. 9 - CEP: 13418-900 - Piracicaba, SP. \\ ${ }^{3}$ Bolsista FAPESP. \\ *Autor correspondente <nussio@carpa.ciagri.usp.br>
}

\begin{abstract}
RESUMO: A correta associação de fontes concentradas de energia e/ou proteína ao volumoso da ração de bovinos, poderá maximizar o desempenho dos animais, como efeito da complementariedade das taxas de degradação de nutrientes. Avaliou-se o efeito de diferentes formas de processamento de milho, níveis de inclusão na dieta e fontes de proteína sobre a digestibilidade dos nutrientes na dieta, parâmetros de fermentação ruminal, bem como o desempenho de vacas leiteiras. Foram utilizadas cinco vacas da raça holandesa em lactação, distribuídas ao acaso em um delineamento experimental do tipo quadrado latino $5 \times 5$. Os tratamentos utilizados foram: silagem de milho, farelo de soja e milho moído (quirera fino) em nível alto; capim elefante, farelo de soja, milho moído em nível alto; capim elefante, farelo de soja, milho moído em nível baixo; capim elefante, farelo de soja, milho floculado $\left(360 \mathrm{~g} \mathrm{~L}^{-1}\right)$ em nível alto; capim elefante, farinha de peixe, milho floculado em nível alto. A dieta contendo capim elefante, milho floculado e farelo de soja em alto nível foi a que mais se aproximou da dieta de silagem de milho nos diversos parâmetros avaliados. A fonte de proteína não degradável no rúmen (PNDR) não apresentou vantagens em relação à fonte convencional de proteína. $O$ fornecimento de baixo nível de concentrado não supriu as deficiências energéticas do capim elefante. A maior eficiência de produção de vacas leiteiras que receberam rações com base em capim elefante simulando pastejo foi observada quando a energia estava disponível no rúmen, seja através do processamento, ou seja da maior inclusão de concentrado na dieta.

Palavras-chaves: digestibilidade, parâmetros de fermentação ruminal
\end{abstract}

\section{STARCH AND PROTEIN SOURCES IN ELEPHANTGRASS-BASED DIETS FOR LACTATING DAIRY COWS}

\begin{abstract}
Ruminant performance may be improved due to association of specific energy and protein supplemental sources by matching nutrient degradation rates on diets. This work aimed to analyze the effects of corn grain processing, concentrate levels and protein sources on nutrient digestibilities, ruminal fermentation parameters, and performance of lactating holstein cows. Treatments were: corn silage with high concentrate level containing soybean meal and finelly ground corn (FGC); green chopped elephant grass (CEG) with high concentrate level containing soybean meal and FCG; CEG with low concentrate level containing soybean meal and FCG; CEG with high concentrate level containing soybean meal and steam flaked corn (SFC) (360 $\mathrm{g} \mathrm{L}^{-1}$ ) and CEG with high concentrate level containing fish meal and SFC. The trial was set up in a $5 \times 5$ latin square design. Overall nutrient digestion, ruminal parameters and milk yield were improved with SFC plus soybean concentrate associated to elephant grass rations. Performance of group fed CEG added with SFC and soybean meal was comparable to the group fed corn silage based ration. Low concentrate ration level or the addition of fish meal did not improve ruminal fermentation, leading to reduced animal performance. In grazing trials with elephant grass, dairy cows present better efficiency when energy availability is enhanced at the ruminal level. The additional energy supply may be achieved by either increasing concentrate level or by altering ruminal starch degradability.

Key words: digestibility, ruminal fermentation parameters
\end{abstract}

\section{INTRODUÇÃO}

A unificação dos mercados internacionais tem levado os produtores a buscar maior eficiência e escala de produção dos produtos de origem animal, possibilitando dessa maneira que continuem competindo no segmento agropecuário.

O Brasil, por ser um país tropical, apresenta condições climáticas favoráveis para a existência de uma grande diversidade de plantas forrageiras, com elevado potencial produtivo, o que permite que essas plantas sejam utilizadas em sistemas de produção intensivos caracterizados pela elevada capacidade de suporte. Essas características podem reduzir os custos de produção, possibilitando maiores produções de leite e carne por unidade de área, tornando o produto animal mais competitivo e a exploração da pecuária mais rentável. O capim elefante (Pennisetum purpureum) 
apresenta um elevado potencial produtivo, sendo considerado uma das forrageiras de maior produção de matéria seca (Vicent-Chandler et al., 1964; Pedreira et al., 1965).

Para que os animais possam demonstrar seu potencial produtivo, é essencial que esses tenham suas exigências nutricionais atendidas através do fornecimento de uma dieta balanceada qualitativa e quantitativamente. Além disso, é necessário conhecer a intensidade e local de digestão de cada nutriente, permitindo dessa forma um suprimento constante e equilibrado de nutrientes para o animal e para os microrganismos digestores.

Nas últimas décadas adotou-se o conceito da necessidade de alimentos que fossem resistentes à degradação ruminal, tornando-os disponíveis principalmente no intestino delgado, visando um maior aporte de nutrientes para o animal. No entanto, quando se utiliza esse tipo de alimento, a disponibilidade de nutrientes para os microrganismos do rúmen pode tornarse excessivamente restrita, reduzindo a sua população e impedindo a expressão máxima da fermentação ruminal, reduzindo principalmente a digestão da porção fibrosa que pode levar ao comprometimento da produção animal. A utilização de alimentos resistentes à degradação ruminal foi preconizada principalmente para as fontes de proteína, denominadas de proteína não degradável no rúmen (PNDR). No entanto, a partir da revisão de experimentos conduzidos com substituição de fontes de proteína degradáveis por fontes não degradáveis no rúmen, Santos (1996); Santos et al. (1998), observaram que o uso de fontes de PNDR não proporcionou aumentos na produção de leite. O perfil inadequado de aminoácidos essenciais nas fontes de PNDR, principalmente o desbalanço na relação entre lisina e metionina foi o fator que mais contribuiu para a não obtenção de resultados positivos. Das fontes de baixa degradabilidade no rúmen, a farinha de peixe é a que apresenta maiores chances de trazer resultados positivos, devido á sua alta qualidade quanto aos níveis de lisina e metionina.

Uma forma de alterar o local e a intensidade de degradação dos alimentos é através do processamento dos grãos utilizados nas dietas. O processamento dos grãos aumenta a sua suscetibilidade à hidrólise enzimática, proporcionando maior digestibilidade do alimento pelos microrganismos do rúmen e enzimas do hospedeiro. O maior efeito do processamento é a mudança do local de digestão de amido do intestino para o rúmen. A floculação de milho e sorgo, comparada à moagem grosseira ou fina, resulta em uma maior digestão ruminal do amido e um maior fornecimento de energia para os microrganismos do rúmen, maximizando a produção de proteína microbiana (Poore et al., 1993).

Os carboidratos estruturais contidos nos alimentos utilizados para a nutrição de ruminantes são representados pela fração fibra em detergente neutro (FDN) e apresentam uma relação inversamente proporcional à densidade energética. Porém, uma mínima quantidade de fibra de qualidade e forma física adequada é essencial para promover um máximo consumo de matéria seca e energia, manter a fermentação ruminal, fornecer precursores para a formação da gordura do leite e prevenir distúrbios metabólicos (NRC, 1989). O aumento na proporção de concentrado ou de grãos na dieta provoca uma redução na digestibilidade da fibra, havendo maiores reduções de acordo com o aumento das proporções de carboidratos não estruturais (Orskov, 1986).

O presente trabalho teve como objetivo avaliar os efeitos da utilização do capim elefante em pastejo simulado como volumoso em dietas de vacas leiteiras, associado a duas fontes de proteína (farelo de soja e farinha de peixe) e duas formas de processamento do grão de milho (moído e floculado), sobre o consumo, digestibilidade dos nutrientes, parâmetros de fermentação ruminal, e produção de leite.

\section{MATERIAL E MÉTODOS}

Foram utilizadas cinco vacas da raça holandesa, com média de 180 dias em lactação, e produção média de leite de $17,3 \mathrm{~kg} \mathrm{dia}^{-1}$, em um delineamento experimental do tipo quadrado latino $5 \times 5$. Os animais foram canulados no rumen e no duodeno, com cânulas do tipo "T". O experimento foi conduzido nas instalações do laboratório de Bromatologia do Departamento de Produção Animal da ESALQ-USP, de junho a outubro de 1999.

As dietas formuladas apresentaram variações quanto à forma de processamento do milho, fonte de proteína e nível de fornecimento do concentrado. Foi utilizada uma dieta à base de silagem de milho e as demais à base de capim elefante como volumoso. Os tratamentos foram compostos da seguinte forma: Silagem de milho, milho moído fino $(1,18 \mathrm{~mm})$ em nível alto e farelo de soja (SMFS); capim elefante, milho moído fino $(1,18 \mathrm{~mm})$ em nível alto e farelo de soja (MM-AFS); capim elefante, milho moído fino $(1,18 \mathrm{~mm})$ em nível baixo e farelo de soja (MM-BFS); capim elefante, milho floculado (360 $\mathrm{g} \mathrm{L}^{-1}$ ) em nível alto e farelo de soja (MF -FS); capim elefante, milho floculado $\left(360 \mathrm{~g} \mathrm{~L}^{-1}\right)$ em nível alto e farinha de peixe (MF-FP). A proporção dos componentes da dieta, e composição química e bromatológica analisada é apresentada na (Tabela 1).

O capim elefante foi cortado manualmente no momento de cada alimentação à altura de $60 \mathrm{~cm}$ acima do solo simulando o pastejo dos animais e imediatamente picado em uma picadora estacionária. A alimentação foi fornecida duas vezes ao dia (6h30 e 18h30) no momento da ordenha dos animais, com consumo de volumoso à vontade, permitindo sobras ao redor de $10 \%$, que foram registradas diariamente. $\mathrm{O}$ concentrado foi ofertado simultaneamente ao volumoso, em nível constante: $6,7 \mathrm{~kg} \mathrm{cab}^{-1}$ dia (alto) e 4,5 $\mathrm{kg} \mathrm{cab}^{-1}$ dia(baixo), resultando em variação na proporção 
volumoso: concentrado durante o período experimental. $\mathrm{Na}$ Tabela 1 é apresentada a participação média de volumoso e de concentrado observada no experimento.

Para caracterizar o capim elefante que foi fornecido aos animais, foram coletadas amostras da forragem durante o período experimental, as quais foram separadas em dois estratos, até $60 \mathrm{~cm}$ do solo, e superior a $60 \mathrm{~cm}$ do solo. As amostras coletadas ainda foram classificadas quanto à altura média em relação ao ponto de inflexão do limbo foliar, e a relação haste/folha.

A silagem de milho foi confeccionada no Departamento de Produção Animal da USP/ESALQ, quando o milho estava no estágio fisiológico farináceo duro. O milho floculado foi produzido por uma empresa comercial para atingir densidade de $360 \mathrm{~g} \mathrm{~L}^{-1}$.

O período experimental teve duração de 75 dias, subdividido em cinco períodos de 15 dias, sendo destinados os sete primeiros dias dos períodos para a adaptação dos animais às novas dietas; os quatro dias subsequentes para incubação de saquinhos de náilon no rúmen dos animais para ensaio de digestibilidade "in situ"; e os quatro últimos dias para as coletas.

Para o ensaio de digestibilidade "in situ" foram colocados 6 gramas de material moído (volumosos em peneira de $5 \mathrm{~mm}$, e grãos em peneira de $2 \mathrm{~mm}$ ) em saquinhos de náilon de $10 \times 20 \mathrm{~cm}$ com porosidade de $45 \mu \mathrm{m}$, previamente pesados. Os sacos foram agrupados de acordo com as dietas que os animais estavam recebendo, e foram submersos no rúmen de todas as vacas, de maneira reversa, de modo que foram retirados todos ao mesmo tempo, para evitar erros na lavagem. Os horários de incubação utilizados foram: 0, 12, 24, 48 e 96 horas para os volumosos; e 0, 6, 12, 24 e 48 horas para os grãos. Os dados das amostras incubadas foram processados utilizando o programa "fit curve" desenvolvido pelo Rowett Research Institute, Aberdeen, Escócia.
As amostras dos alimentos, fezes e conteúdo duodenal foram analisadas quanto ao teor de MS, MO, PB (A.O.A.C, 1990), FDN, FDA (Undersander et al., 1993) e amido (Poore et al, 1989). Os volumosos foram analisados quanto ao teor de nitrogênio solúvel (Krishnamoorthy et. al, 1982). A digestibilidade aparente no rúmen e trato digestivo total foi determinada através da utilização de lignina como marcador interno de indigestibilidade (Besle et al., 1995).

Para análise da variância e comparação de médias foi utilizado o procedimento GLM do programa SAS (1991). As médias, para os parâmetros de desempenho dos animais, foram obtidas através de quadrados mínimos, com a utilização do comando LSMEANS do programa SAS (1991). Os parâmetros de fermentação ruminal foram analisados como parcelas subdivididas através do PROC MIXED do programa SAS, considerando o efeito de evolução temporal. Foram estabelecidos contrastes para avaliação dos efeitos de processamento físico de grãos (MM-AFS vs MF-FS), fonte de proteína (MF-FS vs MF-FP)e nível de adição de concentrado às rações (MM-AFS vs MM-BFS).

\section{RESULTADOS E DISCUSSÃO}

Não houve diferença $(P>0,05)$ de consumo de matéria seca entre as dietas que apresentaram diferentes formas de processamento de milho, fonte de proteína e nível de concentrado na dieta contendo capim elefante, mas o consumo foi maior para a dieta com silagem de milho $(P<0,05)$ (Tabela 2). O tratamento com silagem de milho apresentou maior produção de leite $(P<0,05)$ em relação ao tratamento com baixo nível de concentrado (MM-BFS).

Não houve diferença $(P>0,05)$ para a porcentagem de proteína e produção de gordura entre

Tabela 1 - Composição químico-bromatológica das dietas com base na MS.

\begin{tabular}{lccccc}
\hline & \multicolumn{5}{c}{ Dieta } \\
\cline { 2 - 6 } Composição & Silagem Milho & \multicolumn{4}{c}{ Capim Elefante } \\
\cline { 2 - 6 } & Milho Moído & \multicolumn{2}{c}{ Milho Moído } & \multicolumn{2}{c}{ Milho Floculado } \\
\cline { 2 - 6 } & Farelo Soja & A - FS & B - FS & Farelo Soja & Farinha Peixe \\
\hline Volumoso, \% & 66,9 & 67,2 & 73,1 & 64,8 & 68,3 \\
Concentrado, \% & 33,1 & 32,8 & 26,9 & 35,2 & 31,7 \\
PB, \% & 15,4 & 14,2 & 13,1 & 14,6 & 13,8 \\
NS:NT, \% & 57,2 & 45,1 & 45,1 & 45,1 & 45,1 \\
Amido, \% & 29,4 & 15,3 & 9,2 & 17,9 & 18,7 \\
FDN, \% & 32,8 & 51,8 & 55,0 & 49,9 & 52,3 \\
FD N:ADR & 1,04 & 3,30 & 6,49 & 2,31 & 2,68 \\
FDA, \% & 16,9 & 29,6 & 32,0 & 28,6 & 29,5 \\
Lig, \% & 1,84 & 3,50 & 3,82 & 3,37 & 3,54 \\
\hline A:
\end{tabular}

A: nível alto ; FS: farelo de soja; B: nível baixo; PB: proteína bruta; ${ }^{1} \mathrm{NS}: \mathrm{NT} \%$ : relação $\mathrm{N}$ solúvel e $\mathrm{N}$ total referente aos volumosos das dietas; FDN: fibra em detergente neutro; FDN:ADR: fibra em detergente neutro e amido degradável no rúmen; FDA: fibra em detergente ácido; Lig: lignina 
as dietas. No entanto, houve uma menor quantidade $(P<0,05)$ de proteína no leite das vacas alimentadas com a dieta MM-BFS, diferindo da dieta com silagem de milho. Essa resposta se deve, provavelmente, a uma menor produção de proteína microbiana (dado não apresentado) em decorrência da falta de energia para os microrganismos ruminais, estando de acordo com Friggens et al. (1998). Os efeitos de processamento do grão, fontes de proteína e nível de concentrado não resultaram em diferenças significativas na produção diária de proteína no leite.

$\mathrm{O}$ tratamento MM-BFS apresentou a maior porcentagem de gordura no leite $(P>0,05)$, diferindo dos tratamentos com milho floculado. A maximização da fermentação de amido ruminal, geralmente reduz a digestibilidade de fibra no rúmen, diminuindo a produção relativa de acetato, o precursor de gordura no leite. Além desse fator, a adição de farinha de peixe intensifica a redução da porcentagem de gordura no leite de vacas com produções de leite inferiores a $30 \mathrm{~L} \mathrm{dia}^{-1}$, sendo a porcentagem de proteína do leite não alterada (Santos et al., 1997).

Não foram observadas diferenças significativas para o parâmetro eficiência de conversão alimentar $(P>0,05)$. Nussio (1997) relatou eficiência $8,8 \%$ maior para tratamentos com sorgo floculado em relação à sorgo laminado.

As médias observadas para consumo de matéria seca das dietas (Tabela 3 ) são diferentes daquelas apresentadas na Tabela 2, devido à falta de consistência de alguns valores de digestibilidade calculados, levando à desconsideração de alguns animais nos períodos. A redução do número de repetições de alguns tratamentos, não prejudicou, no entanto, as análises estatísticas. A incapacidade de recuperação completa do marcador, foi geralmente a causa determinante do descarte de alguns valores insatisfatórios. As digestibilidades da MS e MO no rúmen e no trato total foram superiores $(\mathrm{P}<0,05)$ para a

Tabela 2 - Efeito das dietas experimentais sobre o consumo de matéria seca, produção e composição do leite e eficiência alimentar.

\begin{tabular}{|c|c|c|c|c|c|c|c|c|c|}
\hline \multirow{3}{*}{ Parâmetro } & \multirow{3}{*}{$\begin{array}{c}\text { SM } \\
\text { MM } \\
\text { FS }\end{array}$} & \multicolumn{4}{|c|}{ Capim Elefante } & \multirow[b]{3}{*}{ EPM } & \multirow{2}{*}{\multicolumn{3}{|c|}{$\begin{array}{c}\text { Contraste } \\
\mathrm{P}<\end{array}$}} \\
\hline & & \multicolumn{2}{|c|}{ Milho Mo ído } & \multicolumn{2}{|c|}{ Milho Floculado } & & & & \\
\hline & & A-FS & B-FS & FS & FP & & Proc & Prot & Conc. \\
\hline CMS, $\mathrm{kg} \mathrm{dia}{ }^{-1}$ & $19,7^{\mathrm{a}}$ & $17,7^{\mathrm{ab}}$ & $15,5^{b}$ & $16,6^{\mathrm{ab}}$ & $17,0^{\mathrm{ab}}$ & 1,16 & 0,50 & 0,81 & 0,21 \\
\hline $\mathrm{PL}, \mathrm{kg} \mathrm{dia}^{-1}$ & $15,6^{\mathrm{a}}$ & $12,6^{\mathrm{ab}}$ & $10,7^{b}$ & $14,2^{\mathrm{ab}}$ & $13,1^{\mathrm{ab}}$ & 1,65 & 0,51 & 0,65 & 0,43 \\
\hline PLCG , kg dia ${ }^{-1}$ & 15,7 & 12,8 & 11,1 & 13,8 & 12,6 & 1,64 & 0,65 & 0,61 & 0,47 \\
\hline EA & 0,78 & 0,71 & 0,75 & 0,86 & 0,77 & 0,09 & 0,32 & 0,56 & 0,80 \\
\hline \multicolumn{10}{|c|}{ Composição do Leite } \\
\hline Proteína (\%) & 3,35 & 3,17 & 3,17 & 3,15 & 3,22 & 0,10 & 0,87 & 0,64 & 0,96 \\
\hline Proteína (kg) & $0,52^{\mathrm{a}}$ & $0,40^{\mathrm{ab}}$ & $0,34^{b}$ & $0,45^{a b}$ & $0,42^{a b}$ & 0,04 & 0,48 & 0,75 & 0,36 \\
\hline PB leite/ing $(\mathrm{kg})^{1}$ & 0,169 & 0,152 & 0,171 & 0,184 & 0,177 & 0,016 & 0,20 & 0,77 & 0,43 \\
\hline Gordura (\%) & $3,55^{\mathrm{ab}}$ & $3,60^{\mathrm{ab}}$ & $3,76^{a}$ & $3,33^{b}$ & $3,28^{b}$ & 0,13 & 0,20 & 0,80 & 0,43 \\
\hline Gord ura (kg) & 0,55 & 0,45 & 0,40 & 0,47 & 0,43 & 0,05 & 0,78 & 0,58 & 0,52 \\
\hline
\end{tabular}

SM: silagem de milho; MM: milho moído; FS: farelo de soja; CMS: consumo de matéria seca; PL: produção de leite; PLCG: produção de leite corrigido para $3,5 \%$ gordura; EA: eficiência alimentar; ${ }^{1}$ PB no leite/PB ingerida, kg. Proc: efeito de processamento; Prot: efeito de proteína; Conc: efeito de nível de concentrado na dieta. EPM: erro padrão da média.

Médias na mesma linha, seguidas de letras distintas diferem a $5 \%$.

Tabela 3 - Efeito das dietas experimentais sobre o consumo e digestibilidade aparente da matéria seca e matéria orgânica.

\begin{tabular}{|c|c|c|c|c|c|c|c|c|c|}
\hline \multirow{3}{*}{ Parâmetro } & \multirow{3}{*}{$\begin{array}{c}\text { SM } \\
\text { MM } \\
\text { FS }\end{array}$} & \multicolumn{4}{|c|}{ Capim Elefante } & \multirow[b]{3}{*}{ EPM } & \multirow{2}{*}{\multicolumn{3}{|c|}{$\begin{array}{c}\text { Contraste } \\
\mathrm{P}<\end{array}$}} \\
\hline & & \multicolumn{2}{|c|}{ Milho Mo ído } & \multicolumn{2}{|c|}{ Milho Floculado } & & & & \\
\hline & & A-FS & B-FS & FS & FP & & Proc & Prot & Conc \\
\hline CMS $\left(\mathrm{kg} \mathrm{dia}{ }^{-1}\right)$ & $19,68^{a}$ & $17,41^{\mathrm{ab}}$ & $14,94^{b}$ & $16,40^{\mathrm{ab}}$ & $17,31^{\mathrm{ab}}$ & 1,44 & 0,67 & 0,67 & 0,30 \\
\hline DTTMS (\%) & $73,93^{a}$ & $60,59^{b}$ & $62,14^{\mathrm{b}}$ & $65,30^{\mathrm{b}}$ & $65,21^{b}$ & 2,10 & 0,18 & 0,97 & 0,64 \\
\hline DRMS (\%) & 55,04 & 42,79 & 44,64 & 45,70 & 43,28 & 5,47 & 0,74 & 0,76 & 0,83 \\
\hline $\mathrm{CMO}\left(\mathrm{kg} \mathrm{dia}{ }^{-1}\right)$ & $18,55^{\mathrm{a}}$ & $15,78^{\mathrm{ab}}$ & $13,38^{b}$ & $14,90^{\mathrm{ab}}$ & $15,77^{\mathrm{ab}}$ & 1,32 & 0,68 & 0,66 & 0,27 \\
\hline DTTMO (\%) & $75,50^{a}$ & $62,22^{b}$ & $63,45^{\mathrm{b}}$ & $67,08^{b}$ & $66,81^{\mathrm{b}}$ & 2,09 & 0,16 & 0,93 & 0,71 \\
\hline DRMO (\%) & $51,56^{a}$ & $39,74^{a}$ & $41,94^{a}$ & $42,13^{a}$ & $39,65^{b}$ & 5,19 & 0,85 & 0,83 & 0,68 \\
\hline
\end{tabular}

FS: farelo de soja; FP: farinha de peixe; CMS: consumo de matéria seca ;DTTMS: digestibilidade no trato total de MS; DTTTMO: digestibilidade no trato total de MO; DRMS e DRMO: digestibilidade ruminal de MS e MO. EPM: erro padrão da média. Médias na mesma linha, seguidas de letras distintas diferem a $5 \%$. 
dieta contendo silagem de milho em relação às demais dietas. O nível de significância para efeito de processamento do grão de milho na digestibilidade no trato total da MS $(P=0,18)$ e da $M O(P=0,16)$, mostrou maiores valores de digestibilidade para a dieta contendo milho floculado. Essa resposta está de acordo com Joy et al. (1997), que observaram nível de significância $(P=0,09)$ de maior digestibilidade da $\mathrm{MO}$ no trato total para o milho floculado a $310 \mathrm{~g} \mathrm{~L}^{-1}$ em relação ao floculado a $390 \mathrm{~g} \mathrm{~L}^{-1}$.

$\mathrm{O}$ consumo de FDN do tratamento MF-FP diferiu $(P<0,05)$ do tratamento com silagem de milho, que apresentou o menor consumo de FDN devido ao menor teor de FDN nesse volumoso (Tabela 4). Não houve efeito $(P>0,05)$ de processamento, fonte de proteína e nível de concentrado sobre o consumo de FDN. Okine et al. (1997) não observaram diferença no consumo de FDN de animais alimentados com alfafa e suplementados com $50 \%$ ou $35 \%$ de concentrado na dieta. A digestibilidade da FDN no trato total e ruminal não foi diferente entre as dietas $(P>0,05)$.

$O$ consumo de FDA foi superior $(P<0,05)$ para as dietas contendo capim elefante do que para a dieta com silagem de milho. Não houve efeito de processamento, fonte de proteína e nível de concentrado na dieta sobre a ingestão de FDA.

Apesar do fato de que a dieta contendo silagem de milho tenha levado à menor contribuição de FDN e FDA na composição das rações, observou-se menores valores de digestibilidade ruminal e de trato total para a fração parede celular desse volumoso quando comparado ao capim elefante.

O consumo de proteína da dieta com silagem de milho foi superior $(P<0,05)$ aos das dietas MM-BFS e MFFP, que pode ser explicado pelo fato dessas dietas terem apresentado um teor de PB médio inferior às demais dietas. Apesar das dietas terem sido formuladas para ser isoprotéicas, após as análises laboratoriais constatou-se que elas apresentaram diferenças nos níveis de proteína (Tabela 1).

Houve diferença no consumo de PB entre as dietas com alto e baixo nível de concentrado, com nível de significância $(P=0,12)$, devido à diferença de $P B$ nessas dietas. A digestibilidade da proteína no trato total não foi diferente entre as dietas $(P>0,05)$.

Houve maior $(P<0,05)$ consumo de amido no tratamento contendo silagem de milho em relação aos demais tratamentos. O efeito de nível de concentrado na dieta mostrou diferença estatística, com nível de significância $(P=0,15)$, com maior consumo de amido para a dieta com alto nível de concentrado.

As dietas contendo MF diferiram da dieta MMBFS em relação à porcentagem de amido digerida no trato total $(P<0,05)$. Houve efeito de processamento do milho, com nível de significância $(P=0,13)$ sobre este parâmetro, apresentando maiores digestibilidades para o tratamento com milho floculado.

$\mathrm{O}$ uso de dietas à base de silagem de milho reduziu $(P<0,05)$ os valores de $\mathrm{pH}$ e a relação acetato:propionato, e não apresentou efeito $(P>0,05)$ sobre a concentração molar de acetato e dos ácidos graxos voláteis totais no fluído ruminal. Além disso, aumentou $(P<0,05)$ a concentração molar de propionato, butirato e nitrogênio amoniacal no fluido ruminal (Tabela 5 ). Esses dados podem ser explicados pelo maior consumo e quantidade de amido digerido no trato digestivo, o que geralmente determina maior concentração de ácidos orgânicos (principalmente propiônico) durante o processo de fermentação. Associado a isso, a silagem de milho apresentou menor tamanho de partícula, o que deve ter levado à menor taxa de mastigação e ruminação, promovendo redução na secreção de tamponantes salivares e consequente redução do $\mathrm{pH}$ ruminal.

Tabela 4 - Efeito das dietas experimentais sobre o consumo e digestibilidade aparente dos nutrientes.

\begin{tabular}{|c|c|c|c|c|c|c|c|c|c|}
\hline \multirow{3}{*}{ Parâmetro } & \multirow{3}{*}{$\begin{array}{c}\text { SM } \\
\text { MM } \\
\text { FS }\end{array}$} & \multicolumn{4}{|c|}{ Capim Elefante } & \multirow[b]{3}{*}{ EPM } & \multirow{2}{*}{\multicolumn{3}{|c|}{$\frac{\text { Contraste }}{\mathrm{P}<}$}} \\
\hline & & \multicolumn{2}{|c|}{ Milho Mo ído } & \multicolumn{2}{|c|}{ Milho Floculado } & & & & \\
\hline & & A-FS & B-FS & FS & FP & & Proc & Prot & Conc. \\
\hline CFDN $\left(\mathrm{kg} \mathrm{dia}^{-1}\right)$ & $6,62^{b}$ & $9,12^{\mathrm{ab}}$ & $8,66^{\mathrm{ab}}$ & $8,68^{\mathrm{ab}}$ & $9,55^{a}$ & 0,68 & 0,74 & 0,43 & 0,73 \\
\hline DTTFDN (\%) & 53,42 & 54,99 & 57,09 & 56,32 & 57,72 & 3,65 & 0,85 & 0,81 & 0,77 \\
\hline DRFDN (\%) & 51,61 & 57,56 & 54,34 & 53,00 & 55,01 & 5,60 & 0,68 & 0,82 & 0,77 \\
\hline CFDA (kg dia $\left.{ }^{-1}\right)$ & $3,39^{b}$ & $5,23^{a}$ & $5,04^{a}$ & $4,98^{a}$ & $5,42^{a}$ & 0,39 & 0,74 & 0,49 & 0,80 \\
\hline DTTFDA (\%) & 50,33 & 54,77 & 55,77 & 56,48 & 56,35 & 4,01 & 0,82 & 0,98 & 0,89 \\
\hline DRFDA (\%) & 53,20 & 58,90 & 54,25 & 54,81 & 56,07 & 5,58 & 0,71 & 0,88 & 0,67 \\
\hline CPB $\left(\mathrm{kg} \mathrm{dia}{ }^{-1}\right)$ & $3,06^{a}$ & $2,64^{a b}$ & $2,01^{b}$ & $2,50^{\mathrm{ab}}$ & $2,31^{b}$ & 0,20 & 0,69 & 0,56 & 0,12 \\
\hline DTTPB (\%) & 77,81 & 71,61 & 75,73 & 75,80 & 73,06 & 3,21 & 0,45 & 0,59 & 0,49 \\
\hline CAmido $\left(\mathrm{kg} \mathrm{dia}^{-1}\right)$ & $6,02^{a}$ & $2,79^{b}$ & $1,41^{\mathrm{b}}$ & $3,04^{b}$ & $3,07^{b}$ & 0,54 & 0,80 & 0,97 & 0,15 \\
\hline DTTA (\%) & $96,58^{\mathrm{ab}}$ & $96,03^{a b}$ & $95,17^{\mathrm{b}}$ & $98,78^{a}$ & $98,47^{\mathrm{a}}$ & 0,93 & 0,13 & 0,84 & 0,59 \\
\hline DRA ( \%) & 68,61 & 66,83 & 68,08 & 76,27 & 73,79 & 9,10 & 0,57 & 0,87 & 0,93 \\
\hline
\end{tabular}

CFDN, CFDA, CPB, CAmido: Consumo diário de MS, FDN, FDA e Amido. MO: Matéria orgânica; DTTFDN, DTTFDA, DTTA, DTTPB: digestibilidade no trato total de FDA, FDA, amido e PB. DRFDN, DRFDA, DRA, DRPB: digestibilidade ruminal de FDN, FDA, amido e PB. EPM: erro padrão da média. Médias na mesma linha, seguidas de letras distintas diferem a $5 \%$. 
A utilização de milho floculado, aumentou $(P<0,05)$ a concentração de propionato no fluído ruminal, de acordo com Joy et al. (1997); Plascencia \& Zinn (1996) e Menezes Junior (1999). O processamento do grão de milho também aumentou a concentração de butirato e dos ácidos graxos voláteis totais no fluído ruminal, discordando dos dados de Joy et al. (1997); Lykos et al. (1997); Plascencia \& Zinn (1996) e Menezes Jr. (1999). O processamento ainda reduziu $(P<0,05)$ a concentração de nitrogênio amoniacal e a relação acetato:propionato.

Houve efeito $(P<0,05)$ de processamento sobre a concentração molar de acetato no fluído ruminal, com maior concentração no tratamento contendo milho floculado, o que contraria os dados de Plascencia \& Zinn (1996) e Joy et al. (1997) comparando milho laminado com milho floculado, que observaram menores concentrações de acetato quando o milho floculado foi utilizado. O processamento do grão de milho não apresentou efeito $(P>0,05)$ sobre 0 valor de $\mathrm{pH}$; esses dados concordam com Joy et al. (1997) e Menezes Jr. (1999), porém discordam dos dados de Lykos et al. (1997) e Nussio (1997) que relataram reduções nos valores de $\mathrm{pH}$ para as dietas contendo milho floculado. Isso ocorre provavelmente devido à maior digestibilidade do amido do grão de milho floculado, que promove maior disponibilidade de energia para os microrganismos do rúmen a utilizarem para o seu crescimento e reprodução. Esse fato resulta em uma maior taxa de fermentação ruminal, promovendo uma maior concentração de ácidos orgânicos (principalmente propiônico) e uma utilização mais eficiente do nitrogênio disponível no rúmen, sugerindo maior síntese de proteína microbiana, o que reduz a concentração de nitrogênio amoniacal no rúmen.

No presente trabalho, a manutenção do $\mathrm{pH}$ ruminal na presença de grãos floculados talvez se deva ao fato de que o nível mais alto de concentrado não chegou a representar desafio ao ambiente ruminal.

O uso de uma fonte de proteína de menor degradabilidade ruminal promoveu um aumento $(P<0,05)$ da relação acetato:propionato, decorrente da redução $(\mathrm{P}<0,05)$ na concentração molar de propionato e $\mathrm{pH}$ no fluído ruminal. Houve redução na concentração ruminal de nitrogênio amoniacal e dos ácidos graxos voláteis totais, a um nível de significância de $(P=0,06)$ e $(P=0,14)$, respectivamente. Apesar disso, as concentrações molares de acetato e butirato no fluído ruminal não foram alteradas $(P>0,05)$.

O tratamento MM-BFS determinou elevações $(P<0,05)$ na concentração de nitrogênio amoniacal no fluído ruminal. Contudo, não houve efeito sobre os valores de $\mathrm{pH}$, acetato, propionato e da relação acetato:propionato $(P>0,05)$. Houve redução de butirato $(P<0,05)$ e redução na concentração molar total de ácidos graxos voláteis, a um nível de significância de $(P=0,16)$. Essas características podem ser explicadas pela maior proporção de volumoso na dieta (capim elefante), uma vez que os volumosos fornecem uma maior quantidade de precursores para a formação de acetato. Entretanto, dietas contendo elevadas proporções de volumosos apresentam reduzida densidade energética, o que pode levar à redução da disponibilidade de energia para a fermentação ruminal e maior utilização de proteína como fonte de energia, promovendo um aumento na concentração de nitrogênio amoniacal no rúmen.

O desaparecimento da fração a da MS da silagem de milho foi superior $(P<0,05)$ ao capim elefante incubado nas demais dietas devido ao seu maior teor de amido e nitrogênio solúvel na MS, que apresenta fração rapidamente degradável no rúmen (Tabela 6). Os tipos de dieta não influenciaram a degradação da fração a do capim elefante.

A taxa fracional de degradação $\left(\% \mathrm{~h}^{-1}\right)$ não diferiu entre os volumosos das dietas experimentais. No entanto, a fração potencialmente degradável foi superior para a silagem de milho $(P<0,05)$, devido à sua elevada degradabilidade na fração solúvel. A fração efetivamente degradável, considerando uma taxa de passagem de $5 \%$ $\mathrm{h}^{-1}$, foi maior para a MS da silagem de milho, diferindo do capim elefante incubado nas demais dietas $(P<0,05)$. A fração efetivamente degradável do capim elefante incubado foi semelhante entre as dietas, com média igual a $63 \%$, indicando que não houve efeito destas sobre a

Tabela 5 - Efeitos das dietas experimentais sobre as médias dos parâmetros de fermentação ruminal.

\begin{tabular}{|c|c|c|c|c|c|c|c|c|c|}
\hline \multirow{3}{*}{ Parâmetro } & \multirow{3}{*}{$\begin{array}{c}\text { SM } \\
\text { MM } \\
\text { FS }\end{array}$} & \multicolumn{4}{|c|}{ Capim Elefante } & \multirow[b]{3}{*}{ EPM } & \multirow{2}{*}{\multicolumn{3}{|c|}{$\begin{array}{c}\text { Contraste } \\
\mathrm{P}<\end{array}$}} \\
\hline & & \multicolumn{2}{|c|}{ Milho Moído } & \multicolumn{2}{|c|}{ Milho Floculado } & & & & \\
\hline & & A-FS & B-FS & FS & FP & & Proc & Prot & Conc. \\
\hline$\overline{\mathrm{pH}}$ & $6,21^{\mathrm{b}}$ & $6,59^{a}$ & $6,63^{a}$ & $6,63^{a}$ & $6,54^{a}$ & 0,04 & 0,27 & 0,01 & 0,25 \\
\hline $\mathrm{N}-\mathrm{NH} 3\left(\mathrm{mg} \mathrm{dL}^{-1}\right)$ & $20,9^{a}$ & $16,8^{b}$ & $20,5^{a}$ & $14,2^{\mathrm{c}}$ & $11,7^{d}$ & 1,00 & 0,05 & 0,06 & 0,007 \\
\hline$A G V$ total $\left(\mathrm{mM} \mathrm{L}^{-1}\right)$ & 77,7 & 70,9 & 68,7 & 78,9 & 75,7 & 5,84 & 0,0003 & 0,14 & 0,16 \\
\hline $\mathrm{C}_{2}\left(\mathrm{mM} \mathrm{L}^{-1}\right)$ & 50,6 & 50,7 & 49,9 & 54,9 & 53,5 & 4,18 & 0,004 & 0,35 & 0,33 \\
\hline $\mathrm{C}_{3}\left(\mathrm{mM} \mathrm{L}^{-1}\right)$ & $18,9^{a}$ & $13,7^{b}$ & $13,0^{b}$ & $16,8^{\mathrm{ab}}$ & $15,3^{b}$ & 1,30 & 0,0001 & 0,02 & 0,26 \\
\hline $\mathrm{C}_{4}\left(\mathrm{mM} \mathrm{L}^{-1}\right)$ & $8,1^{a}$ & $6,5^{\mathrm{b}}$ & $5,7^{b}$ & $7,1^{\mathrm{ab}}$ & $6,8^{\mathrm{ab}}$ & 0,73 & 0,005 & 0,23 & 0,0004 \\
\hline $\mathrm{C}_{2}: \mathrm{C}_{3}$ & $2,74^{c}$ & $3,72^{\mathrm{ab}}$ & $3,85^{a}$ & $3,35^{b}$ & $3,76^{\mathrm{ab}}$ & 0,22 & 0,02 & 0,01 & 0,46 \\
\hline
\end{tabular}

$\mathrm{N}-\mathrm{NH}_{3}$ : nitrogênio amoniacal ( $\left.\mathrm{mg} \mathrm{dL}^{-1}\right)$; AGV: ácidos graxos voláteis $\left(\mathrm{mM} \mathrm{L}^{-1}\right)$; C2: acetato $\left(\mathrm{mM} \mathrm{L}^{-1}\right)$; C3: propionato (mM L-1); C4: butirato $\left(\mathrm{mM} \mathrm{L}^{-1}\right)$; C2:C3: relação acetato propionato. Médias na mesma linha , seguidas de letras distintas diferem a $5 \%$. 
degradabilidade da MS do capim elefante. Balsalobre (1996) observou extensão de degradação da MS de capim elefante em pastejo simulado de $67,9 \%$.

O desaparecimento da fração a da MS dos grãos de milho moído e floculado incubados nas diferentes dietas não apresentaram diferenças $(P>0,05)$. Houve de diferença para as formas de processamento do grão de milho, tendo o milho floculado incubado nas dietas de capim elefante apresentado menor desaparecimento ruminal na fração a, a um nível de significância de $(P=0,19)$.

A taxa fracional de degradação da MS do grão de milho incubado nas diferentes dietas foi superior na dieta com alto nível de concentrado, diferindo da dieta com silagem de milho $(P<0,05)$. Houve efeito de processamento do grão de milho, a um nível de significância de $(P=0,16)$, indicando efeito negativo da floculação sobre a taxa de degradação da matéria seca do grão de milho $\left(\% \mathrm{~h}^{-1}\right)$. Isso contraria relatos na literatura (Nussio, 1997) onde a maior intensidade de processamento do grão foi praticamente correlacionado com a taxa de degradação. Por outro lado, sugere que a moagem do grão deve ter sido intensa, aumentando significativamente a degradação ruminal do amido.

A porcentagem potencialmente degradável da MS do milho no rúmen foi semelhante para as incubações nas diferentes dietas, diferindo apenas para a dieta MF-FP. A presença desta fonte de proteína determinou redução no potencial de degradação da MS do grão de milho floculado $(P<0,05)$.

A porcentagem efetivamente degradável da MS do grão de milho moído incubado na dieta com alto nível de concentrado foi semelhante à dieta de baixo nível de concentrado e diferente das demais dietas $(P<0,05)$.
Esse fato, possivelmente, foi devido à maior taxa fracional de degradação da dieta MM-AFS. Houve efeito das formas de processamento sobre a fração efetivamente degradável da MS dos grãos de milho, com efeito positivo para o milho moído $(P<0,05)$. Quanto ao nível de concentrado na dieta, houve superioridade da fração efetivamente degradável no rúmen do grão de milho incubado na dieta MM-AFS, em um nível de significância de $(P=0,12)$.

A Tabela 7 demostra que o desaparecimento da fração a da FDN da silagem de milho foi superior $(P<0,05)$ em relação às dietas com milho moído. $A$ degradabilidade da fração $b$ e a taxa fracional de degradação da FDN da silagem de milho diferiu das demais dietas $(P<0,05)$. A porcentagem de FDN potencialmente degradável no rúmen do tratamento com silagem de milho foi superior ao capim elefante incubado nas demais dietas $(P<0,05)$, devido aos maiores valores de degradabilidade da FDN nas frações a e b. Esse tratamento também apresentou porcentagem de FDN efetivamente degradável no rúmen superior $(P<0,05)$. $O$ capim elefante incubado nas dietas apresentou maiores taxas de degradação fracional, permitindo maiores quantidades de FDN degradável no rúmen. A fração solúvel da FDA do capim elefante incubado nas dietas com milho moído foram inferiores à dieta com silagem de milho, indicando a maior qualidade do FDA da silagem de milho $(P<0,05)$. A taxa fracional de degradação não diferiu entre os tratamentos $(P>0,05)$. A porcentagem potencialmente e efetivamente degradável da FDA da silagem de milho foi significativamente superior ao FDA do capim elefante incubado nas demais dietas $(P<0,05)$, sugerindo qualidade superior do FDA da silagem de milho (Tabela 7).

Tabela 6 - Parâmetros de degradabilidade "in situ" da matéria seca dos volumosos e grãos de amido incubados nas diferentes dietas.

\begin{tabular}{|c|c|c|c|c|c|c|c|c|c|}
\hline \multirow{3}{*}{ Parâmetro } & \multirow{3}{*}{$\begin{array}{l}\text { SM } \\
\text { MM } \\
\text { FS }\end{array}$} & \multicolumn{4}{|c|}{ Capim Elefante } & \multirow[b]{3}{*}{ EPM } & \multirow{2}{*}{\multicolumn{3}{|c|}{$\begin{array}{c}\text { Contraste } \\
\mathrm{P}<\end{array}$}} \\
\hline & & \multicolumn{2}{|c|}{ Milho Mo ído } & \multicolumn{2}{|c|}{ Milho Floculado } & & & & \\
\hline & & A-FS & B-FS & FS & FP & & Proc & Prot & Conc. \\
\hline \multicolumn{10}{|l|}{ Volumoso } \\
\hline$A(\%)$ & $39,0^{a}$ & $21,4^{b}$ & $21,2^{b}$ & $22,5^{\mathrm{b}}$ & $21,9^{b}$ & 1,37 & 0,57 & 0,74 & 0,92 \\
\hline B (\%) & $42,6^{b}$ & $48,4^{\mathrm{ab}}$ & $48,2^{\mathrm{ab}}$ & $48,2^{\mathrm{ab}}$ & $50,0^{a}$ & 2,26 & 0,93 & 0,57 & 0,95 \\
\hline $\mathrm{C}^{1}\left(\% \mathrm{~h}^{-1}\right)$ & 3,62 & 3,92 & 4,55 & 4,16 & 3,56 & 0,004 & 0,70 & 0,34 & 0,35 \\
\hline Pot degradavel ${ }^{2}$ & $81,6^{a}$ & $69,9^{b}$ & $69,5^{\mathrm{b}}$ & $70,7^{b}$ & $71,9^{b}$ & 1,65 & 0,71 & 0,62 & 0,88 \\
\hline Ef degradável ${ }^{3}$ & $64,7^{a}$ & $62,9^{b}$ & $63,0^{\mathrm{b}}$ & $63,0^{\mathrm{b}}$ & $63,0^{b}$ & 0,16 & 0,61 & 0,86 & 0,79 \\
\hline \multicolumn{10}{|l|}{ Grãos de milho } \\
\hline$A(\%)$ & 25,3 & 27,3 & 23,4 & 21,9 & 21,5 & 2,87 & 0,19 & 0,93 & 0,38 \\
\hline $\mathrm{B}(\%)$ & 80,5 & 75,3 & 82,0 & 79,4 & 77,8 & 3,51 & 0,42 & 0,74 & 0,22 \\
\hline $\mathrm{C}^{1}\left(\% \mathrm{~h}^{-1}\right)$ & $4,56^{b}$ & $6,66^{a}$ & $5,40^{\mathrm{ab}}$ & $5,80^{\mathrm{a}}$ & $5,56^{\mathrm{ab}}$ & 0,004 & 0,16 & 0,69 & 0,06 \\
\hline Pot degra davel ${ }^{2}$ & $99,9^{a}$ & $99,7^{\mathrm{a}}$ & $100^{a}$ & $99,8^{a}$ & $98,7^{b}$ & 0,26 & 0,87 & 0,01 & 0,56 \\
\hline Ef degradável ${ }^{3}$ & $72,9^{b}$ & $76,3^{a}$ & $74,6^{\mathrm{ab}}$ & $73,8^{\mathrm{b}}$ & $72,5^{\mathrm{b}}$ & 0,71 & 0,02 & 0,20 & 0,12 \\
\hline
\end{tabular}

${ }^{1} \mathrm{kd}=$ taxa fracional de degradação $\left(\% \mathrm{~h}^{-1}\right) ;{ }^{2} \%$ potencialmente degradável $(\mathrm{a}+\mathrm{b}) ;{ }^{3} \%$ efetivamente degradável $(\mathrm{kp}=$ taxa de passagem $=$ $\left.5 \% \mathrm{~h}^{-1}\right)$.

Médias na mesma linha, seguidas de letras distintas diferem a $5 \%$. 
Tabela 7 - Parâmetros de degradabilidade "in situ" da FDN e FDA dos volumosos incubados nas diferentes dietas.

\begin{tabular}{|c|c|c|c|c|c|c|c|c|c|}
\hline \multirow{3}{*}{ Parâmetro } & \multirow{3}{*}{$\begin{array}{c}\text { SM } \\
\text { MM } \\
\text { FS }\end{array}$} & \multicolumn{4}{|c|}{ Capim Elefante } & \multirow[b]{3}{*}{ EPM } & \multirow{2}{*}{\multicolumn{3}{|c|}{$\begin{array}{c}\text { Contraste } \\
\mathrm{P}<\end{array}$}} \\
\hline & & \multicolumn{2}{|c|}{ Milho Mo ído } & \multicolumn{2}{|c|}{ Milho Floculado } & & & & \\
\hline & & A-FS & B-FS & FS & FP & & Proc & Prot & Conc. \\
\hline \multicolumn{10}{|l|}{ FDN do volumoso } \\
\hline $\mathrm{A}(\%)$ & $11,4^{\text {a }}$ & $5,4^{\mathrm{b}}$ & $6,1^{\mathrm{b}}$ & $8,0^{a b}$ & 6,7 ab & 1,49 & 0,26 & 0,56 & 0,77 \\
\hline B (\%) & $73,7^{\text {a }}$ & $61,4^{b}$ & $60,0^{b}$ & $59,34^{b}$ & $62,36^{\mathrm{b}}$ & 1,45 & 0,34 & 0,16 & 0,53 \\
\hline $\mathrm{C}^{1}\left(\% \mathrm{~h}^{-1}\right)$ & $1,92^{b}$ & $3,72^{a}$ & $4,3^{a}$ & $4,02^{a}$ & $3,46^{a}$ & 0,003 & 0,54 & 0,22 & 0,26 \\
\hline Pot degra davel ${ }^{2}$ & $85,1^{a}$ & $66,9^{b}$ & $66,1^{\mathrm{b}}$ & $67,3^{b}$ & $69,1^{\mathrm{b}}$ & 1,58 & 0,88 & 0,54 & 0,73 \\
\hline Ef degra dável ${ }^{3}$ & $62,9^{a}$ & $62,7^{\mathrm{b}}$ & $62,7^{\mathrm{b}}$ & $62,7^{\mathrm{b}}$ & $62,8^{b}$ & 0,04 & 0,84 & 0,44 & 0,76 \\
\hline \multicolumn{10}{|l|}{ FDA do volumoso } \\
\hline$A(\%)$ & $9,37^{a}$ & $2,22^{b}$ & $1,80^{b}$ & $4,32^{a b}$ & $3,47^{a b}$ & 1,98 & 0,51 & 0,79 & 0,90 \\
\hline B (\%) & $72,9^{a}$ & $65,0^{b}$ & 66,0 ab & $63,3^{b}$ & $66,8^{a b}$ & 1,90 & 0,58 & 0,27 & 0,75 \\
\hline $\mathrm{C}^{1}\left(\% \mathrm{~h}^{-1}\right)$ & 2,50 & 3,35 & 3,83 & 3,62 & 3,07 & 0,004 & 0,68 & 0,42 & 0,51 \\
\hline Pot degra davel ${ }^{2}$ & $82,3^{a}$ & $67,3^{\mathrm{b}}$ & $67,8^{\mathrm{b}}$ & $67,7^{b}$ & $70,2^{b}$ & 3,06 & 0,93 & 0,60 & 0,91 \\
\hline Ef degra dável ${ }^{3}$ & $62,9^{a}$ & $62,7^{\mathrm{b}}$ & $62,7^{\mathrm{b}}$ & $62,7^{b}$ & $62,7^{\mathrm{b}}$ & 0,04 & 0,74 & 0,74 & 0,91 \\
\hline
\end{tabular}

${ }^{1} \mathrm{kd}=$ taxa fracional de degradação $\left(\% \mathrm{~h}^{-1}\right) ;{ }^{2} \%$ potencialmente degradável $(\mathrm{a}+\mathrm{b}) ;{ }^{3} \%$ efetivamente degradável $(\mathrm{kp}=$ taxa de passagem $=5 \% \mathrm{~h}^{-1}$ ).

Médias na mesma linha, seguidas de letras distintas diferem a $5 \%$.

\section{CONCLUSÕES}

O fornecimento de fontes suplementares de energia e proteína de maior disponibilidade ruminal amplificou a digestão de nutrientes na dieta, e ofereceu melhores condições para o desempenho dos animais.

A associação de grãos de milho fisicamente processados e farelo de soja em dietas à base de capim elefante, conciliou eficiência de parâmetros de digestão de nutrientes e produção dos animais, assemelhando-se às dietas baseadas em silagem de milho.

A elevação no nível de concentrado oferecida aos animais, em simulação ao pastejo de gramíneas tropicais, otimizou as condições de digestão e do ambiente ruminal. Contudo, esses níveis não foram críticos e elevados o suficiente para determinar alterações negativas nos parâmetros de fermentação ruminal. Seria conveniente explorar níveis mais elevados de concentrado, em pesquisas futuras, no sentido de observar esse comportamento.

\section{REFERÊNCIAS BIBLIOGRÁFICAS}

ASSOCIATION OF OFFICIAL ANALYTICAL CHEMISTS. Official method of analysis. 12.ed. Washington, D.C., 1990.

BALSALOBRE, M.A.A. Desempenho de vacas em lactação sob pastejo rotacionado de capim-elefante (Pennisetum purpureum, Schum.). Piracicaba, 1996. 139p. Dissertação (Mestrado) - Escola Superior de Agricultura "Luiz de Queiroz", Universidade de São Paulo.

BESLE, J.M.; JOUANY, J.P.; CORNU, A. Transformations of structural phenylpropanoids during cell wall digestion. FEMS Microbiology Reviews, v.16, p.33-52, 1995.

FRIGGENS, N.C.; EMMANS, G.C.; KYRIAZAKIS, I.; OLDHAM, J.D.; LEWIS, M. Feed intake relative to stage of lactation for dairy cows consuming total mixed diets with a high or low ratio of concentrate to forage. Journal of Dairy Science, v.81, p.2228-2239, 1998.
JOY, M.T.; De PETERS, J.; FADEL, J.G.; ZINN, R.A. Effects of corn processing on the site and extent of digestion in lactating cows. Journal of Dairy Science, v.80, p.2087-2097, 1997.

KRISHNAMOORTHY, U.C.; MUSCATO, T.V.; SNIFFEN, C.J.; VAN SOEST, P.J. Nitrogen fractions in selected feedstuffs. Journal of Dairy Science, v.65, p.217-225, 1982.

LYKOS, T.; VARGA, G.A.; CASPER, D. Varying degradation rates of total nonstructural carbohydrates: Effects on ruminal fermentation, blood metabolites and milk production and composition in high producing holstein cows. Journal of Dairy Science, v.80, p.3341-3355, 1997.

MENEZES JR., M.P. Efeito do processamento do grão de milho e sua substituição parcial por polpa de citros peletizada sobre o desempenho, digestibilidade de nutrientes e parâmetros sanguíneos de vacas de leite. Piracicaba, 1999. 97p. Dissertação (Mestrado) - Escola Superior de Agricultura "Luiz de Queiroz", Universidade de São Paulo.

NATIONAL RESEARCH COUNCIL. Nutrient requirements of dairy cattle. 6.ed. Washington: NRC, 1989. 157p.

NUSSIO, L.G. Effects on NDF levels and ruminally degradable starch on performance, ruminal parameters and in situ degradation of nutrients in lactating dairy cows fed sorghum diets. Tucson, 1997. 139p. Thesis (Ph.D.) - University of Arizona.

OKINE, E.K.; KHORASANI, G.R.; KENNELLY, J.J. Effects of source of forage and level of concentrate on chewing activity and milk production response in late lactation cows. Canadian Journal of Animal Science, v.77, p.253-258, 1997.

ORSKOV, E.R. Starch digestion and utilization in ruminant. Journal of Animal Science, v.63, p.1624-1633, 1986.

PEDREIRA, J.V.S.; WERNER, J.C.; ROCHA, G.L.; CINTRA, B. Estudos preliminares de introdução de plantas forrageiras no sul do Estado de São Paulo. In: CONGRESSO INTERNACIONAL DE PASTAGENS, 9., São Paulo, 1965. Anais. São Paulo, 1965. p.1537-1541.

PLASCENCIA, A.; ZINN, R.A. Influence of flake density on the feeding value of steam-processed corn in diets for lactating cows. Journal of Animal Science, v.74, p.310-316, 1996.

POORE, M.H.; ECK, T.P.; SWINGLE, R.S.; THEURER, C.B. Total starch and relative starch availability of feed grains. $20^{\text {th }}$ Biennial Conference on Rumen Function, Chicago, 1989. Abstr.35, 1989. 
POORE, M.H.; MOORE, J.A.; ECK, T.P.; SWINGLE, R.S.; THEURER, C.B. Effect of fiber source and ruminal starch degradability on site and extent of digestion in dairy cows. Journal of Dairy Science, v.76, p.2244-2253, 1993.

SANTOS, F.A.P. Conceitos atuais de nutrição proteica. In: SIMPÓSIO SOBRE PRODUÇÃO ANIMAL, 9., Piracicaba, 1996. Confinamento de bovinos; anais. Piracicaba: FEALQ, 1996. p.51-68.

SANTOS, F.A P.; HUBER, J.T.; THEURER, C.B.; SWINGLE. R.S.; SIMAS. J.M. Response of lactating cows to various densities of sorghum grain. Journal of Animal Science, v.75, p.16811685, 1997.

SANTOS, F.A.P.; SANTOS, J.E.P.; THEURER, C.B.; HUBER, J.T. Effects of rumen undegradable protein on dairy cow performance: a 12 year literature review. Journal of Dairy
Science, v.81, p.3182-3213, 1998.

SAS INSTITUTE. SAS users guide: statistics. 5.ed. Cary: Statistical Analysis System Institute, 1991.

UNDERSANDER, D.; MERTENS, D.R.; THIEX, N. Forage analyses procedures. Omaha: National Forage Testing Association, 1993. 153p.

VICENT-CHANDLER, J.; CARO-COSTAS, R.; PEARSON, R.W.; ABRUÑA, F.; FIGARELA, J.; SILVA, S. The intensive management of tropical forages in Puerto Rico. Puerto Rico: Agricultural Experiment Station, University of Puerto Rico, 1964. 152p.

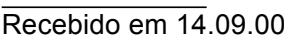

